\title{
The effect of knowledge sharing on the relationship between empowerment, service innovative behavior and entrepreneurship
}

\section{Shadi Abualoush ${ }^{a}$, Abdallah Mishael Obeidat ${ }^{b}$, Nader Mohammad Aljawarneh ${ }^{b}$, Shaker Al- Qudah $^{c}$ and Khaled Bataineh ${ }^{d}$}

${ }^{a}$ Management Information system (MIS), Faculty of Financial and Business Science, Irbid National University, Jordan

${ }^{b}$ Jadara University, Jordan

${ }^{c}$ Faculty of Business, Applied Science Private University, Jordan

${ }^{d}$ Business Administration, Faculty of Administrative Science and Finance, Irbid National University, Jordan

\section{CH R O N I C L E A B S T R A C T}

Article history:

Received: July 23, 2021

Received in revised format: September 18, 2021

Accepted: December 18, 2021

Available online: December 20, 2021

Keywords:

Empowerment

Knowledge sharing

Creative work behavior

Leadership

\begin{abstract}
This study is aimed at exploring the effect of empowerment on creative work and entrepreneurship behavior. It is also aimed at identifying the mediating role of sharing knowledge between them. The relevant data were collected through a questionnaire from (9) Jordanian commercial banks, where (340) questionnaires were distributed to workers in the Jordanian commercial banks. In addition, a statistical analysis was used to show the relationship between the variables and draw the conclusions. The results of the study show there is an empowering effect on creative work behavior through knowledge sharing. Moreover, it also showed that there was an empowering effect on entrepreneurship through knowledge sharing. This study does, to a large extent, bridge the gaps within the literature and develops an understanding of how to empower employees in order to increase their creative behavior, make them entrepreneurs, and enhance the same through knowledge sharing. The results of this study indicate that there are certain important benefits for the workers in the banking industry which can be gained through facilitating more innovative behavior among their employees. The results also indicate that employee's empowerment and enhancing knowledge sharing are essential to creative and entrepreneurial work behavior.
\end{abstract}

(C) 2022 by the authors: licensee Growing Science, Canada

\section{Introduction}

The term "creativity" refers to an idea, practice, or project that is seen as brandy by an individual or any other adopting unit (Rogers, 2003). Meanwhile, creative behavior is an initiative of the employees related to introducing new processes, new products, new markets, or groups in the organization (Amo \& Kolvereid, 2005) along with their ability to generate and implement new and useful ideas at work (Scott \& Bruce, 1994). However, as for service innovations, we refer to the successful development of a new service, including carrying out innovative activities on any scale to improve and modify the services along with characteristics that make them differ on the current services. Esmaeilzadeh (2011) and Nightingale (1985) indicated that it has become essential for the employees of service institutions to show creative behavior to obtain a competitive advantage and hence achieve sustainable growth. Therefore, these institutions must maintain customer satisfaction and loyalty if they want to have an advantage. It is worth stating that competitiveness promoting innovative employee service behavior has emerged as a major goal of various organizations, and, accordingly, posing a great challenge to managers as they strive to find out the relevant ways to develop and maintain innovative behavior at work (Garg, \& Dhar, 2017). Moreover, possessing creativity in establishing entrepreneurial projects which formed the main factor in the economic growth, whether financially

* Corresponding author.

E-mail address: SHADI HABES@inu.edu.jo (S. Abualoush)

(C) 2022 by the authors; licensee Growing Science, Canada. doi: $10.5267 /$ j.ijdns.2021.12.012 
by increasing the GDP and hence providing employment opportunities or morally through raising the level of human capital capacity, and then, achieving sustainable development. According to (Hytti et al., (2010)) the drive to initiate entrepreneurship has a tremendous effect on the employee's motivation and innovation.

Therefore, creativity and entrepreneurship can be considered as continuous and integrated processes. In addition, creativity is deemed as the source of entrepreneurship, and which allows creativity to flourish and achieve its economic and social value (Zhao, 2005). Hence, the characteristics of the innovative behavior of the employee indicate that the vast majority of employees can be creative, and that the development of the potential capabilities of the employee is vital, due to the fact that the distinguishing feature of the innovative behavior of employees is the goal of achieving the entrepreneurial idea (Jaaffar et al., 2018). Besides, entrepreneurship is important in influencing the desire to innovate and revealing the talents or behaviors of individuals that can maintain the competitive advantage and when institutions take the time, the same is risk-taking, innovative, and proactive with respect to its overall business operations, product and technology offerings, and interactions with competitors. Therefore, the employees can realize that a work environment has a high level of leadership (i.e. a combination of innovation, risk-taking and pro-active). Also, it can stimulate employee perception in relation to an environment of work which then supports innovation, risk-taking, and proactive individual results (Kör, 2016).

In this regard, human resources are considered the most influential, most valuable and costly capital in the organization. Therefore, empowerment is a new option for the senior managers to use workers in leading the organizations in this competitive world (Hasani \& Sheikhesmaeili, 2016). Hence, empowerment is granting decision-making powers to a team or individual. Besides, this matter encourages the employee to have a strong sense of motivation, since all employees should be empowered to make decisions, implement programs, and use their innovative capabilities (Al-Dweik et al., 2016). Also, it is a kind of delegated authority and / or responsibility by subordinate superiors. (Appelbaum et al., 2014)

On the other hand, scholars look at empowerment as a process, an outcome, or both, where empowerment transforms individuals into active agents who work according to their values and interests. In other words, the empowered individual shall work to solve the salient problems they or their community face and to change the components of the social systems that may cause such problems (Perkins \& Zimmerman, 1995; Joo et al, 2020). Therefore, the distinction between empowerment processes and outcomes is critical to define empowerment theory clearly. Individual's empowerment processes include participation in the community organizations. Meanwhile, at the organizational level, enabling processes may include a group of decision-making and shared leadership. Moreover, empowerment processes at the community level may include collective actions to access government and other community resources (Such as the media). The delegated outcomes refer to the empowerment processes that allow us to study the outcomes of empowerment processes. Meanwhile, individual delegated outcomes may include the ability to control a specific situation and skills for resource mobilization. Therefore, when we study organizations, the outcomes include organizational network development, organizational growth, and political influence. Empowerment outcomes at the community level include evidence of pluralism, organizational alliances, and accessible community resources (Perkins \& Zimmerman, 1995).

The social interaction is considered as an indispensable channel for improving knowledge exchange between the departments, as social interactions between employees from different departments enhance knowledge flows (Yuan et al., 2020) and the basis for such interactions is the individual who creates knowledge and interacts with other individuals by sharing knowledge to create new knowledge (Nonaka \& Takeuchi, 1995). This means that sharing knowledge is making knowledge available to others within the organization) (Ipe, 2003). In addition, knowledge sharing refers to the task of helping others with knowledge and cooperating with others to solve problems, develop new ideas, or implement processes (Cummings, 2004). Accordingly, the importance of knowledge sharing is highlighted by providing a link between the individual and the organization and by transferring existing knowledge with individuals to the organizational level, where it is converted into an economic and competitive value for the organization. Besides, the interactions between individuals who possess diverse and different knowledge enhance the organization's ability to innovate beyond what is possible for anyone to achieve it (Ipe, 2003; Obeidat \& Otibi, 2015). Murray (2012) pointed out the approaches to knowledge sharing, which focus on the methodologies used to facilitate the process of Knowledge sharing, i.e.: the social approach, which focuses on social methodologies such as trust, commitment, culture, and individuals 'attitudes towards knowledge sharing, in addition to its focus on sharing tacit knowledge. Furthermore, the second approach, the technological approach, focuses on the comfortable and fast channels that facilitate the process of sharing knowledge. The economic approach, which focuses on the benefits and costs are expected to be obtained from the knowledge-sharing process.

It is worth noting that the effective institutional performance system, in addition to its development of a set of quantitative and qualitative standards aimed at increasing productivity, tries to create standards to measure the level of satisfaction of the beneficiaries of the concerned service so as to identify their trends towards the level of service provided. Hence, this has led to a change in the trends and patterns of behavior of those dealing with the administration. Accordingly, the importance of the study has emerged in providing a practical framework that links the dimensions and components of knowledge sharing and its impact on the relationship between empowerment, creative behavior, and entrepreneurship, in addition to the results and recommendations it will present that benefit the stakeholders in the Jordanian private institutions to improve the performance of these institutions in providing their services, at the level of studies conducted in Jordan and the Arab region, and based on the importance of empowerment and knowledge sharing, which in the end enhances creative service behavior and pioneering 
work, except these concepts have rarely been studied together. Many of these studies have focused on the bilateral aspects between these concepts, such as the relationship between knowledge sharing and entrepreneurship, or between knowledge sharing and service-based creative behavior, as well as the relationship between empowerment and service-based creative behavior, besides the relationship between empowerment and entrepreneurship. However, these studies were not able to explore the factors that affect the creative service behavior and entrepreneurship in a more comprehensive way, such as knowledge sharing as a mediating role between empowerment, creative service behavior and entrepreneurship. Therefore, and in order to address these gaps, the current study helps through the mediating role of the relationship between empowerment and creative service behavior and entrepreneurship in Jordanian commercial banks.

\section{Research Model \& Hypotheses development}

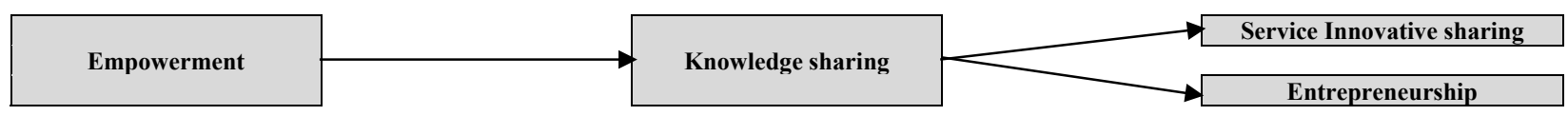

Fig. 1. The proposed study

\subsection{Knowledge sharing, Empowerment, Service Innovative behavior}

It is worth mentioning that the findings from research studies on how empowerment affects innovative work behavior remain scarce and, in many cases, unconvincing (Berraies et al., 2014) and between (Kmieciak et al. 2012) that there is no significant relationship between empowerment and innovative work behavior in small and medium-sized companies, recognizing that the group of empirical studies that study employee empowerment and innovation is minimal. Some of the results related to the previous studies on the effect of knowledge exchange and on creative ability are ambiguous, since some indicate that knowledge exchange supports and enhances the behavior of creative work (Zhu \& Mu, 2016; Mura et al., 2013). In addition to the effect of external and internal knowledge on behavior Innovative work, it was found that the external knowledge can provide employees with new insights, and, thus, contribute to innovative behavior (Kang \& Lee, 2017) However, knowledge sharing is an essential tool for promoting innovative behavior in employees and facilitating innovative activities (Wang et al., 2017). In addition, when knowledge is shared between employees, they are more likely to develop, integrate and translate information rather than simply pass it on to recipients $(\mathrm{Zu} \& \mathrm{Mu}, 2016)$.

Thus, the way to understand empowerment of employees is assured most often through the exchange of knowledge, improvement of intellectual capacity, in addition to autonomy during decision-making (Karim \& Rehman, 2012). Sangar and Rangnekar (2014) confirmed that when individuals are convinced that they are empowered to make decisions, in addition to risk relation with the performance of certain tasks, they will generate creative ideas and solutions that contribute to the effectiveness of the organization as a whole. Therefore, delegating the authority, cooperation, and a shared vision, in addition to communication and knowledge sharing, is a rationale that will create an environment where all employees feel encouraged and motivated, which will, thus, generate their confidence in their knowledge, experiences, and their desire to unleash innovative ideas. (Abukhait et al., 2019). Furthermore, participatory decision-making and coaching behavior of an empowering leader will encourage knowledge sharing within the team (Shahab et al., 2019) where the individuals may feel a high level of independence when it comes to performing a certain behavior and when the employee perceives self-determination to freely choose their goals based on self-interest, curiosity, care, or established values (Wang, 2016). Thus, when the employees feel more empowered by management, they become more likely to develop a higher level of organizational definition by accepting organizational values and goals as their own (Erturk, 2010).

On the other hand, Jiang et al. (2016) stated that the psychological empowerment of individuals within a group encourages effective personal participation in group activities, which may lead to enhancing the individual's personal confidence within the group, thus, facilitating the exchange of personal knowledge. It is worth mentioning that various studies have found out that empowering individuals can encourage their behavior in the exchange of knowledge because empowered individuals usually tend to develop self-confidence and the positive impact of their actions. Therefore, they are more likely to engage in behavior that can make a difference from their point of view (Kang et al., 2017; Saffar \& Obeidat, 2020)

In this regard, it is worth noting that teamwork in teams may empower employees and help them develop the concept of autonomy, which is a major source for improving organizational commitment and reducing stress that leads to creative behavior for employees (Ooko, 2013). According to Daniel and Jardon (2015), there is a link between organizational commitment, commercial motivation, and the spirit of personality towards creativity and creative behavior. Thus, the organizational commitment and its widespread acceptance are important and beneficial to both the organization and its employees, as it helps in enhancing feelings of belonging, job security, career development, improving compensation, and high remuneration (Azeem \& Akhtar, 2014). On the other hand, and in the study of Kang et al. (2016), the impact of innovative and risky organizational climate on the innovative behavior of employees was examined and thus highlighted the importance of an organizational ecosystem that supports the entrepreneurial process.

$\mathbf{H}_{1}$ : Knowledge sharing mediates the relationship between Empowerment \& Service Innovative behaviors. 


\subsection{Knowledge sharing, Empowerment, Entrepreneurship}

Knowledge sharing is considered as an important component of many initiatives, as it can lead to efficiency, flexibility, and adaptability to face risks and uncertainties, and increase the search for opportunities, learning and innovation activities; (Stewart, 2009; De Clercq et al., 2013). Also, it enables knowledge to be better used as a powerful tool to influence a greater entrepreneurial direction, it does not only lead to product and market efficiencies, but, also, to practical and managerial competencies that lead to improved performance ( $\mathrm{Li}$ et al., 2009). So, entrepreneurial orientation involves the search for opportunities through the allocation of large resources including knowledge, which also requires and promotes knowledge accumulation and transfer, besides, recognition of opportunities and the search for information, and promoting knowledge collection and exchange among the members of the organization (Tuan, 2015; Obeidat, 2019). In the meantime, knowledge can only be shared if each member is given sufficient opportunity to express opinions, ideas, criticism, and comments of other members (Setyanti, et al., 2013). Furthermore, the process of sharing knowledge helps people to exchange implicit and explicit knowledge in addition to generating new knowledge among the targeted people (Birasnav, 2014; Abualoush et al., 2018).

Hashim and Tan (2015) stated in their study that there is a positive relationship between commitment and intention to share knowledge. The studies have also found a direct link to knowledge sharing in adaptability, flexibility, commitment to learning and job satisfaction, which in turn leads to improved competencies and performance of leaders (Yang, 2008; Riege, 2005). Therefore, entrepreneurship is considered as an important factor in production that can lead to economic growth, increased productivity and access to new and high-quality technology, products, and services (Zorn, 2004). The openness of communication is an important precedent for innovation, as it enables the exchange of ideas, knowledge, and information. Such exchanges will in turn lead to innovative and pioneering results (Hülsheger et al., 2009). This is what the entrepreneur needs through economic opportunities and benefiting from the benefits of information. Thus, entrepreneurship provides new job opportunities through the company's innovations, explores new markets, and raises new skills and capabilities. (Dei, 2019)

In this context, entrepreneurship has focused on empowerment more than control strategies, which encourages subordinates to be independent and proactive in seeking and exploiting new business opportunities, therefore, entrepreneurial leadership may be expected to promote the various aspects of empowerment (Miao et al., 2018).

\section{$\mathbf{H}_{2}$ : Knowledge sharing mediates the relationship between Empowerment \&Entrepreneurship.}

\section{Research methodology}

\subsection{Sample and data collection}

In order to achieve the objectives of the study, and to answer its questions, the study has adopted the descriptive, analytical, quantitative approach to describe the phenomenon in question, which is the effect of empowerment on creative service behavior and entrepreneurship in the presence of knowledge sharing as an intermediate variable, where a questionnaire was designed, since this approach helped reveal the problem of the study, leading to its analysis and interpretation according to scientific foundations, with the aim of reaching valuable results that increase the knowledge balance. Thus, the researcher relied on verifying the validity of the study tool by presenting it to several arbitrators who are owners. Experience and specialization in the subject matter of study was studied in several Jordanian universities so as to express an opinion regarding it in terms of its suitability to collect data related to the study, its clarity, coherence and cohesion, and the referees' observations, suggestions, and considering were considered. The procedures for reviewing the questionnaire and auditing it by the competent arbitrators, considering the observations and suggestions, and adjusting are considered as a test of the apparent validity of the tool, and, therefore, it is considered valid for the measurement process for what it was designed for.

The study population consisted of all the Jordanian commercial banks, out of which (13) were registered with the Jordanian Banks Association. For this reason, it is easy to collect data from these banks, and (9) banks have agreed to conduct the study and distribute questionnaires to them. The inspection and analysis unit that the study targeted consisted of various administrative levels in those banks, and the reason for choosing all administrative levels is that all levels in banks are responsible for implementing the general policy set by the bank, thus facilitating creative behavior and entrepreneurial work in a better way. A simple random sample was selected from the study population, where the number of distributed questionnaires reached (340) questionnaires for the study sample, (325) questionnaires were retrieved, and (8) questionnaires were excluded due to their inaccuracy due to non-completion of respondents. Thus, the number of questionnaires valid for analysis became (317), with a percentage $(93 \%)$. The distribution indicated that $73 \%$ of the respondents were male. On the level side of education, $77 \%$ of respondents were found to be at undergraduate and postgraduate levels.

\subsection{Variable measurement}

The questionnaire was used in this study in order to collect the primary data, as the questionnaire consisted of two parts, the first section was for set for demographic variables, which include gender, age, and educational level, and the second part of the questionnaire are the variables that measure the variables described in this study to include empowerment, sharing of

knowledge, and creative behavior. Accordingly, service, entrepreneurship, and to ensure the validity and reliability of 
research, variables were measured using elements that were developed and used in previous studies. All the combinations were measured by using multiple items. In the meantime, all the variants were measured via a five-point Likert scale (1 strongly disagree, 5 - strongly agree) to measure each variable.

\section{3 validity}

The validity of the study's measurement scales was confirmed using exploratory factor analysis (EFA). EFA was carried out using the extraction method of principal component analysis (PCA) and the rotation method of varimax. Questions for the four scales have shown factor loading more than 0.40. Table 1 reports the output of the EFA.

Table 1

EFA of the measurement scales

\begin{tabular}{|c|c|c|c|c|}
\hline Item & ENT & INBEH & EMP & KNSHAR \\
\hline ENT 1 & .688 & & & \\
\hline ENT 2 & .758 & & & \\
\hline ENT 3 & .799 & & & \\
\hline ENT 4 & .775 & & & \\
\hline ENT 5 & .761 & & & \\
\hline ENT 6 & .723 & & & \\
\hline ENT 7 & .815 & & & \\
\hline ENT 8 & .775 & & & \\
\hline ENT 9 & .800 & & & \\
\hline INBEH1 & & .815 & & \\
\hline INBEH2 & & .764 & & \\
\hline INBEH3 & & .852 & & \\
\hline INBEH4 & & .813 & & \\
\hline INBEH5 & & .779 & & \\
\hline INBEH6 & & .755 & & \\
\hline EMP1 & & & .861 & \\
\hline EMP2 & & & .846 & \\
\hline EMP3 & & & .853 & \\
\hline EMP4 & & & .856 & \\
\hline EMP5 & & & .825 & \\
\hline EMP6 & & & .796 & \\
\hline EMP7 & & & .778 & \\
\hline EMP8 & & & .794 & \\
\hline EMP9 & & & .794 & \\
\hline EMP10 & & & .787 & \\
\hline EMP11 & & & .764 & \\
\hline KNSH1 & & & & .663 \\
\hline KNSH2 & & & & .617 \\
\hline KNSH3 & & & & deleted \\
\hline KNSH4 & & & & deleted \\
\hline KNSH5 & & & & deleted \\
\hline KNSH6 & & & & .889 \\
\hline KNSH7 & & & & .748 \\
\hline KNSH8 & & & & .890 \\
\hline KNSH9 & & & & .745 \\
\hline KNSH10 & & & & .709 \\
\hline
\end{tabular}

\subsection{Reliability}

The reliability of measurement scales was tested based on Cronbach's $\alpha$-coefficient. The four scales demonstrated good reliability values more than the minimum suggested value of $\alpha \geq 0.70$ (Hair et al., 2010). These values reflect the reliability, credibility, and internal consistency of the scales (Hair et al., 2010). Cronbach's $\alpha$-coefficient, means, and standard deviations are reported in Table 2.

Table 2

Cronbach's alpha and descriptive statistics of the measurement scales

\begin{tabular}{cccc}
\hline Measurement scale & Mean & Standard deviation & Cronbach's alpha \\
\hline Entrepreneurship & 3.46 & .884 & .912 \\
Innovative behavior & 3.61 & .770 & .885 \\
Empowerment & 3.74 & .761 & .785 \\
Knowledge sharing & 3.65 & 0.949 & 0.872 \\
\hline
\end{tabular}

\section{Results}

To test H1, the procedure was introduced by Baron and Kenny (1986). This procedure has four steps that allow testing all the study hypotheses. The first step includes testing the contribution of the independent variable (IV) on the dependent variable 
(DV). The results show that empowerment has a significant impact on Service Innovative behavior. The second step includes testing the contribution of the IV to the mediator. The results show that the impact of empowerment on knowledge sharing is positive and significant. In step three, the contribution of the mediator to the DV should be tested. The effect of knowledge sharing on Service Innovative behavior was also positive and significant. In the last step, both the IV and the mediator were regressed to the DV. Both empowerment and knowledge sharing show positive and significant contribution to Service Innovative behavior as reported in Table 3. According to Baron and Kenny (1986), if the direct effect of the IV on the DV (obtained in step 1) becomes insignificant in step 4, then full mediation exists. However, if the direct effect decreased while remaining significant, this implies the existence of partial mediation. The results revealed partial mediation as the contribution of empowerment to Service Innovative behavior reduced in step 4, but still significant. Therefore, hypothesis H1 is accepted (partial mediation effect). Table 3 shows the results of testing hypothesis H1.

Table 3

Regression analysis to test hypothesis $\mathrm{H} 1$

\begin{tabular}{|c|c|c|c|c|}
\hline Variables & $\begin{array}{c}\text { Step } 1 \\
\text { INN behavior }\end{array}$ & $\begin{array}{c}\text { Step } 2 \\
\text { K sharing }\end{array}$ & $\begin{array}{c}\text { Step } 3 \\
\text { INN behavior }\end{array}$ & $\begin{array}{c}\text { Step } 4 \\
\text { INN behavior }\end{array}$ \\
\hline (Constant) & $1.327 * * *$ & $1.209 * * *$ & $0.937 * * *$ & $0.868 * *$ \\
\hline Empowerment & $0.757 * * *$ & $0.797 * * *$ & & $0.450 * * *$ \\
\hline $\mathrm{K}$ sharing & & & $0.744 * * *$ & $0.385 * * *$ \\
\hline $\mathrm{R}$ & 0.757 & 0.797 & 0.744 & 0.792 \\
\hline $\mathrm{R}^{2}$ & 0.753 & 0.635 & 0.553 & 0.627 \\
\hline Adjusted $\mathrm{R}^{2}$ & 0.572 & 0.634 & 0.552 & 0.625 \\
\hline F-value & $424.149 * * *$ & $549.182 * * *$ & $390.450 * * *$ & $264.146^{* * * *}$ \\
\hline
\end{tabular}

Note: $* * * p<0.01 ; * * \mathrm{p}<0.05$

To test H2, the procedure introduced by Baron and Kenny (1986). This procedure has four steps that allow testing all the study hypotheses. The first step includes testing the contribution of the independent variable (IV) on the dependent variable (DV). The results show that empowerment has significant impact on entrepreneurship. The second step includes testing the contribution of the IV to the mediator. The results show that the impact of empowerment on knowledge sharing is positive and significant. In step three, the contribution of the mediator to the DV should be tested. The effect of knowledge sharing on entrepreneurship was also positive and significant. In the last step, both the IV and the mediator were regressed to the DV. Both empowerment and knowledge sharing show positive and significant contribution to entrepreneurship as reported in Table 4. According to Baron and Kenny (1986), if the direct effect of the IV on the DV (obtained in step 1) becomes insignificant in step 4, then full mediation exists. However, if the direct effect decreased while remaining significant, this implies the existence of partial mediation. The results revealed partial mediation as the contribution of empowerment to entrepreneurship reduced in step 4, but still significant. Therefore, hypothesis H2 is accepted (partial mediation effect). Table 4 shows the results of testing hypothesis $\mathrm{H} 2$.

Table 4

Regression analysis to test hypothesis $\mathrm{H} 2$

\begin{tabular}{|c|c|c|c|c|}
\hline Variables & $\begin{array}{c}\text { Step } 1 \\
\text { Entrep. }\end{array}$ & $\begin{array}{c}\text { Step } 2 \\
\text { K sharing }\end{array}$ & $\begin{array}{l}\text { Step } 3 \\
\text { Entrep. }\end{array}$ & $\begin{array}{l}\text { Step } 4 \\
\text { Entrep. }\end{array}$ \\
\hline (Constant) & $1.267 * * *$ & $1.209^{* * *}$ & $1.028 * * *$ & $0.938 * *$ \\
\hline Empowerment & $0.826 * * *$ & $0.797 * * *$ & & $0.596 * *$ \\
\hline $\mathrm{K}$ sharing & & & $0.764 * * *$ & $0.288 * * *$ \\
\hline $\mathrm{R}$ & 0.826 & 0.797 & 0.764 & 0.844 \\
\hline $\mathrm{R}^{2}$ & 0.682 & 0.635 & 0.583 & 0.713 \\
\hline adjusted $\mathrm{R}^{2}$ & 0.681 & 0.634 & 0.582 & 0.711 \\
\hline F-value & $679.118 * * *$ & $549.182 * * *$ & $440.723 * * *$ & $389.580 * * *$ \\
\hline
\end{tabular}

Note: $* * * \mathrm{p}<0.01 ; * * \mathrm{p}<0.05$

\section{Discussion and conclusion}

\subsection{Theoretical implications}

This study is aimed at identifying the effect of knowledge sharing on the relationship between empowerment, creative service behavior and entrepreneurship in Jordanian commercial banks. Based on that, a conceptual model was developed that represents the study variables. In order to achieve the objectives of the study, two hypotheses were developed and tested, using the (SPSS) program, where the results of the first hypothesis test showed an empowering effect on creative work behavior through knowledge sharing. Abukhait et al. (2019) suggest that when employees believe (or feel) they are empowered, they are better equipped and more likely to volunteer to generate creative ideas to improve their work environment and the well-being of their organization. This is because the feelings of empowerment give them a greater sense of control over their work environment and thus enhance their ability to innovate (or engage in innovative behaviors). In other words, empowerment often means more flexibility given to employees which in turn encourages them to explore new ways of working through innovative ideas. Furthermore, the study showed an empowering effect on knowledge sharing, that is, when employees have a high level of trust in their colleagues, they tend to care about each other more, and therefore, they are more willing to make an effort in 
sharing knowledge to benefit each other (Wang et al., 2019; Bin Mahfodh \& Obeidat, 2020). ), as it has been stated that there is an effect of sharing in creative work behavior, as knowledge is crucial to the innovation process and for employees to demonstrate innovative behavior, they must acquire, interact with, and disseminate knowledge (Thornhill, 2006), and hence merge it and translate it instead of just passing it on to the recipients. Of course, this stimulates participation in creative work behavior, which includes seeking opportunities for change and applying it to the current business practices. Researchers have drawn attention to employee empowerment as a major factor in innovation (Fernandez \& Moldogaziev, 2013; Al Qudah et al., 2020).

Besides, the results of the second hypothesis test also showed that there is an effect of empowerment in entrepreneurship through knowledge sharing, as entrepreneurship is a form of empowerment based on a fact that it provides a means for individuals to achieve their dreams. Idea generation is at the heart of entrepreneurship and includes evaluating new opportunities. So, there are many different types of entrepreneurships including social, technological, sports and international that provide a way to unlock ideas and share knowledge. Entrepreneurship, which acts as a form of empowerment, provides a means for practitioners and researchers to make a positive contribution to society (Ratten, 2020). Entrepreneurs with a strong perception of efficiency, self-determination, meaning and influence, will be more proactive and exhibit more proactive performance characteristics. Empowerment may help entrepreneurs become confident in their ability to influence their business and their environment. (Henao-Zapata \& Peiró, 2018). This is how the mutual reinforcement between empowerment and entrepreneurship can occur. Empowerment and entrepreneurship may interact in an enhanced cycle towards active performance and change. Entrepreneurial success may lead to perceptions of efficiency, self-determination, meaning and impact. These insights can, then, be leveraged to enable more proactive and innovative procedures. Empowerment and entrepreneurship are both constructs that describe active "bottom-up" processes toward changes in the business environment. Therefore, it is possible to think that empowerment and entrepreneurship are complementary and mutually beneficial. However, complementarity and reciprocity do not imply that both occur simultaneously, nor that they have the same effects, influence, or power (Boudrias et al., 2014). On the other hand, the practice of knowledge sharing in entrepreneurship is very important to obtain new information on how to process self-improvement, new technologies and ideas, solve problems and create core competencies, and start new projects (Muniady et al., 2015; obeidat et al., 2020), as many previous studies have proven Knowledge sharing strongly enhances corporate entrepreneurship. Thus, organizations, aiming to leverage existing assets to develop new business and enter new markets, must strongly promote knowledge sharing (Ahmad \& Karim, 2019).

\subsection{Practical Implications}

Our findings indicate that some of the important benefits to those in the banking industry can be gained by facilitating more innovative behavior among their employees. Furthermore, our findings indicate also that employee empowerment and enhanced knowledge sharing are essential to creative and entrepreneurial business behavior. Thus, this may indicate that managers and decision-makers should promote employee empowerment through a variety of means such as (1) delegating authority to employees in order to achieve the goals of the bank, (2) organizing training programs that help develop the creativity of the bank's employees, (3) Providing employees with resources and modern means of communication, and managers can also promote knowledge sharing in banks through methods such as (1) involving bank workers with information, skills and knowledge available to experts, (2) providing training programs to develop a culture of knowledge sharing, (3) motivating workers In banks to share knowledge, these actions will, in turn, increase employee participation in innovative behavior.

This research also made several practical contributions. First, this study elucidates in more detail about the relationship between empowerment and creative work behavior. This study concluded that empowerment could increase creative work and entrepreneurship behavior. Moreover, knowledge sharing as a mediating variable provides new discovery and has significantly contributed to research on innovative business behavior and entrepreneurship. Second, this study also provides guidance for employees of Jordanian commercial banks to empower employees, and managers should pay more attention to employee ideas and opinions. Moreover, banks need a culture of sharing good knowledge in the banking environment, to allow employees to share ideas more freely.

\subsection{Limitations and Suggestions for Future Studies}

The study has several limitations. First: by reviewing the literature, it was found out that there are few studies that measure the effect of knowledge sharing on the relationship between empowerment, creative service behavior and entrepreneurship. Second, the study was applied to the Jordanian commercial banks, and, thus, the generalization of the results will be limited only to the banks under study. In the future, research studies are needed to enhance the findings of the current study and increase the generalizability of the findings. Therefore, the investigative research should be supplemented with some qualitative tools such as the use of centered interviews or unstructured interviews in such a study. However, bank officials were not in favor of using such tools due to their special status and timing. Thus, this study requires conducting large-scale future research to cover a larger sample to gain more generalization about the work system of organizations in Jordan. Further research can examine technology-based and IT-based organizations so as to test the proposed linkages in the relevant context. 


\section{References}

Abualoush, S. H., Obeidat, A. M., Tarhini, A., Masa'deh, R. E., \& Al-Badi, A. (2018). The role of employees' empowerment as an intermediary variable between knowledge management and information systems on employees' performance. VINE Journal of Information and Knowledge Management Systems, 48(2), 217-237.

Abukhait, R. M., Bani-Melhem, S., \& Zeffane, R. (2019). Empowerment, knowledge sharing and innovative behaviours: Exploring gender differences. International Journal of Innovation Management, 23(01), 1950006.

Ahmad, F., \& Karim, M. (2019). Impacts of knowledge sharing: a review and directions for future research. Journal of Workplace Learning, 31(3), 207-230.

Al-Dweik, G., Al-Daken, L. I., Abu-Snieneh, H., \& Ahmad, M. M. (2016). Work-related empowerment among nurses: literature review. International Journal of Productivity and Quality Management, 19(2), 168-186.

Al-Qudah, S., Obeidat, A. M., \& Shrouf, H. (2020). The impact of strategic human resources planning on the organizational performance of public shareholding companies in Jordan. Problems and Perspectives in Management, $18(1), 219$.

Åmo, B. W., \& Kolvereid, L. (2005). Organizational strategy, individual personality and innovation behavior. Journal of Enterprising Culture, 13(01), 7-19.

Appelbaum, S. H., Karasek, R., Lapointe, F., \& Quelch, K. (2014). Employee empowerment: factors affecting the consequent success or failure-Part I. Industrial and Commercial Training, 46(7), $379-386$

Azeem, S. M., \& Akhtar, N. (2014). Job satisfaction and organizational commitment among public sector employees in Saudi Arabia. International Journal of Business and Social Science, 5(7), 127-133.

Berraies, S, M Chaher \& KB Yahia (2014). Employee empowerment and its importance for trust, innovation and organizational performance. Business Management and Strategy, 5(2), 82-103.

Bin Mahfodh, A. B. S., \& Obeidat, A. M. (2020). Knowledge Sharing Tools and their Impact on Enhancing Organizational Performance. Sciences, 10(9), 91-112.

Birasnav, M. (2014). Knowledge management and organizational performance in the service industry: The role of transformational leadership beyond the effects of transactional leadership. Journal of Business Research, 67, 1622-1629. https://doi.org/10.1016/j.jbusres.2013.09.006

Boudrias, J. S., Morin, A. J. S., \& Lajoie, D. (2014). Directionality of the associations between psychological empowerment and behavioural involvement: A longitudinal autoregressive cross-lagged analysis. Journal of Occupational and Organizational Psychology, 87(3), 437-463.

Cummings, J. N. (2004) Work groups, structural diversity, and knowledge sharing in a global organization. Management Science, 50(3), 352-364.

Daniel J. L., \& Jardon R. C. (2015). The relationship between individual spirituality, organizational commitment and individual innovative behavior. Management Research And Practice, 7(1), 5-13

De Clercq, D., Dimov, D., \& Thongpapanl, N. (2013). Organizational social capital, formalization, and internal knowledge sharing in entrepreneurial orientation formation. Entrepreneurship Theory and Practice, 37(3), 505-537.

Dei, D. G. J. (2019). Entrepreneurship and the Application of Knowledge Management Practices in Ghana. Global Journal of Management And Business Research.

Erturk, A. (2010). Exploring predictors of organizational identification: moderating role of trust on the associations between empowerment, organizational support, and identification. European Journal of Work and Organizational Psychology, 19(4), 409-441.

Esmaeilzadeh, P. (2011). How to Manage and Flourish Innovation in Hospitals' Clinical IT?, Academy of Health Care Management Journal, 7(2), 69-88.

Fernandez, S., \& Moldogaziev, T. (2013). Using employee empowerment to encourage innovative behavior in the public sector. Journal of Public Administration Research and Theory, 23(1), 155-187.

Garg, S., \& Dhar, R. (2017). Employee service innovative behavior. International Journal of Manpower, 38(2) 242-258

Hashim, K. F., \& Tan, F. B. (2015). The mediating role of trust and commitment on members' continuous knowledge sharing intention: A commitment-trust theory perspective. International Journal of Information Management, 35(2), 145-151

Henao-Zapata, D., \& Peiró, J. M. (2018). The importance of empowerment in entrepreneurship. In Inside the Mind of the Entrepreneur (pp. 185-206). Springer, Cham.

Hülsheger, U. R., Anderson, N., \& Salgado, J. F. (2009). Team-level predictors of innovation at work: a comprehensive metaanalysis spanning three decades of research. Journal of Applied Psychology, 94(5), 1128-1145.

Hytti, U., Stenholm, P., Heinonen, J., \& Seikkula-Leino, J. (2010). Perceived learning outcomes in entrepreneurship education: The impact of student motivation and team behaviour. Education and Training, 52(8/9), 587-606

Ipe, M. (2003). Knowledge sharing in organizations: A conceptual framework. Human Resource Development Review, 2(4), 337-359.

Jaaffar, A. H., Ganesan, Y., \& Isa, A. (2018). Employees' Motivation to Undertake Entrepreneurship and Innovative Behavior: UNITEN KSHAS. Global Business \& Management Research, 10(3).

Jiang, X., Flores, H. R., Leelawong, R., \& Manz, C. C. (2016). The effect of team empowerment on team performance: A cross-cultural perspective on the mediating roles of knowledge sharing and intra-group conflict. International Journal of Conflict Management, 27(1), 62-87.

Joo, D., Woosnam, K. M., Strzelecka, M., \& Boley, B. B. (2020). Knowledge, empowerment, and action: testing the empowerment theory in a tourism context. Journal of Sustainable Tourism, 28(1), 69-85. 
Kang, J. H., Matusik, J. G., Kim, T.-Y., \& Phillips, J. M. (2016). Interactive effects of multiple organizational climates on employee innovative behavior in entrepreneurial firms: A cross-level investigation. Journal of Business Venturing, 31(6), 628-642.

Kang, M., \& Lee, M.J. (2017). Absorptive capacity, knowledge sharing, and innovative behaviour of R\&D employees. Technology Analysis \& Strategic Management, 29(2), 219-232.

Karim, F., \& Rehman, O. (2012). Impact of job satisfaction, perceived organizational justice and employee empowerment on organizational commitment in semi-government organizations of Pakistan. Journal of Business Studies Quarterly, 3(4), 92-104.

Hasani, K., \& Sheikhesmaeili, S. (2016). Knowledge management and employee empowerment: A study of higher education institutions. Kybernetes, 45(2), 337-355.

Kmieciak, R., Michna, A., \& Meczynska, A. (2012). Innovativeness, empowerment and IT capability: Evidence from SMEs. Industrial Management \& Data Systems, 112(5), 707-728.

Kör, B. (2016). The mediating effects of self-leadership on perceived entrepreneurial orientation and innovative work behavior in the banking sector. SpringerPlus, 5(1), 1-15.

Li, Y.H., Huang, J.W. , \& Tsai, M.T. (2009). Entrepreneurial orientation and firm performance: The role of knowledge creation process. Industrial Marketing Management, 38(4), 440-449.

Miao, Q., Newman, A., Schwarz, G., \& Cooper, B. (2018). How leadership and public service motivation enhance innovative behavior. Public Administration Review, 78(1), 71-81.

Muniady, R. A., Mamun, A. A., Rosli Mohamad, M., Yukthamarani Permerupan, P., \& Binti Zainol, N. R. (2015). The effect of cognitive and relational social capital on structural social capital and micro-enteprise performance. Sage Open, 5, 1-9.

Mura, M., Lettieri, E., Radaelli, G., \& Spiller, N. (2013). Promoting professionals' innovative behaviour through knowledge sharing: the moderating role of social capital. Journal of Knowledge Management, 17(4), 527-544.

Nightingale, M. (1985). The hospitality industry: defining quality for a quality assurance programme-a study of perceptions. The Service Industries Journal, 5(1), 9-2.

Nonaka, I., \& Takeuchi, H. (1995) The knowledge creating company: How Japanese companies create the dynamics of innovation. New York: Oxford University Press

Obeidat, A. (2019). IT Adaption with Knowledge Conversion Process (SECI). Management Science Letters, 9(13), 22412252

Obeidat, A. M., \& Otibi, G. A. (2015). The impact of knowledge sharing tools on levels of organizational learning (Field Study on Jordanian Commercial Banks). Australian Journal of Basic and Applied Sciences, 9(5), 253-267.

Obeidat, A. M., Abualoush, S. H., Irtaimeh, H. J., Khaddam, A. A., \& Bataineh, K. A. (2018). The role of organisational culture in enhancing the human capital applied study on the social security corporation. International Journal of Learning and Intellectual Capital, 15(3), 258-276.

Ooko, P. A. (2013). Impact of teamwork on the achievement of targets in organisations in Kenya.A case of SOS children's villages, Eldoret (Master's dissertation, University of Nairobi)

Perkins, D. D., \& Zimmerman, M. A. (1995). Empowerment theory, research, and application. American Journal of Community Psychology, 23(5), 569-579.

Ratten, V. (2020). Entrepreneurship as Empowerment: Knowledge spillovers and entrepreneurial ecosystems. Emerald Publishing Limited.

Riege, A., 2005. Three dozen knowledge sharing barriers managers must consider. Journal of Knowledge Management, 9(3): 18-35.

Rogers, E. M. (2003). Diffusion of innovations. $5^{\text {th }}$ ed., London. UK: Free Press.

Saffar, N., \& Obeidat, A. (2020). The effect of total quality management practices on employee performance: The moderating role of knowledge sharing. Management Science Letters, 10(1), 77-90.

Sangar, R., \& Rangnekar, S. (2014). Psychological empowerment and role satisfaction as determinants of creativity. AsiaPacific Journal of Management Research and Innovation, 10(2), 119-127.

Scott, S. G., \& Bruce, R.A. (1994). Determinants of innovative behavior: A path model of individual innovation in the workplace. Academy of Management Journal, 37, 580-607

Setyanti, S. W. L. H., Troena, E. A., Nimran, U., \& Rahayu, M. (2013). Innovation role in mediating the effect of entrepreneurship orientation, management capabilities and knowledge sharing toward business performance: Study at Batik SMEs in East Java Indonesia. IOSR J. Business Management, 8(4), 16-27.

Shahab, A., Sobari, A., \& Udin, U. D. I. N. (2019). Empowering Leadership and OCB: The Roles of Psychological Empowerment and Emotional Intelligence. Wseas Transactions on Business and Economics, 16, 97-106.

Stewart, J.T. (2009). An investigation of an entrepreneurial orientation among employees in service organizations. Unpublished doctoral dissertation, Ohio State University, US.

Thornhill, S. (2006). Knowledge, innovation and firm performance in high-and low technology regimes. Journal of Business Venturing, 21(5), 687-703.

Tuan, L. T. (2015). From corporate social responsibility, through entrepreneurial orientation, to knowledge sharing. The Learning Organization, 22(2), 74-92.

Wang, J., Yang, J., \& Xue, Y. (2017). Subjective well-being, knowledge sharing and individual innovation behavior: The moderating role of absorptive capacity. Leadership \& Organization Development Journal, 38(8), 1110-1127. 
Wang, W. T., Wang, Y. S., \& Chang, W. T. (2019). Investigating the effects of psychological empowerment and interpersonal conflicts on employees' knowledge sharing intentions. Journal of Knowledge Management, 23(6), 1039-1076.

Wang, W.T. (2016). Examining the influence of the social cognitive factors and relative autonomous motivations on employees' knowledge sharing behaviors. Decision Sciences, 47(3), 404-436.

Yang, C.W. (2008). The relationships among leadership styles, entrepreneurial orientation and business performance. Managing Global Transitions, 6(3), 257-275.

Yuan, X., Olfman, L., \& Yi, J. (2020). How do institution-based trust and interpersonal trust affect interdepartmental knowledge sharing?. In Information Diffusion Management and Knowledge Sharing: Breakthroughs in Research and Practice (pp. 424-451). IGI Global.

Zhao, F. (2005). Exploring the synergy between entrepreneurship and innovation. International Journal of Entrepreneurial Behavior and Research, 11(1), 25-41.

Zhu, C., \& Mu, R. (2016). Followers' innovative behavior in organizations: The role of transformational leadership, psychological capital and knowledge sharing. Frontiers of Business Research in China, 10(4), 636.

Zorn, O. (2004). Influence of entrepreneurial capital on entrepreneurial dynamics. Economic and Business Review for Central and South-Eastern Europe, 6(3), 195.

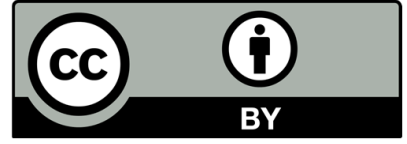

(C) 2022 by the authors; licensee Growing Science, Canada. This is an open access article distributed under the terms and conditions of the Creative Commons Attribution (CC-BY). license (http://creativecommons.org/licenses/by/4.0/). 